\title{
Korean Late-Talkers' Use of the Mutual Exclusivity Assumption on First versus Second Label Learning
}

\author{
Il-Ran Choi ${ }^{\mathrm{a}}$, Mina Hwang ${ }^{\mathrm{b}}$ \\ ${ }^{a}$ Department of Speech-Language Therapy, Graduate School of Special Education, Dankook University, Youngin, Korea \\ ${ }^{b}$ Department of Special Education, Dankook University, Youngin, Korea
}

\author{
Correspondence: Mina Hwang, $\mathrm{PhD}$ \\ Department of Special Education, Dankook \\ University, 152 Jukjeon-ro, Suji-gu, Yongin 448-701, \\ Korea \\ Tel: +82-31-8005-3816 \\ Fax: +82-31-8021-7144 \\ E-mail: hwangm@dankook.ac.kr \\ Received: June 20, 2014 \\ Revised: July 15, 2014 \\ Accepted: July 31, 2014 \\ This paper was based partly on the master's thesis \\ of the first author.
}

\begin{abstract}
Objectives: In the present study, we investigated late-talkers' use of the mutual exclusivity assumption as they inferred the meaning of a novel-word in two different conditions: when a novel word could be the first label of a non-familiar object and when a novel word was the second label of a familiar object. Methods: Fourteen Korean late-talkers age 24 to 35 months and fifteen typically developing peers participated in this study. In Experiment 1, the children were given photos of two objects, one familiar and the other non-familiar, and asked to choose the photo of a novel-word spoken by the examiner. In Experiment 2, the examiner showed the children a photo of a familiar object and used a novel-word (ex, pooty) as its label. Then, the children were shown a photo of that familiar object and a photo of a non-familiar object, and asked to choose which photo corresponded with the novel-word. Results: In Experiment 1, both groups tended to choose non-familiar objects for the novelwords; there was no significant difference between the groups in the frequency of choosing non-familiar objects. In Experiment 2, while the typically developing children tended to map the novel words to the previously shown familiar objects (ignoring the mutual exclusivity assumption), the late-talkers tended to map the novel words to the non-familiar objects. Conclusion: The bias toward mutual exclusivity shown in late-talkers may be useful in learning the first label of an object, but it can restrict acquisition of the various vocabulary related to that object.
\end{abstract}

Keywords: Late-talker, Mutual exclusivity assumption, Mapping of word meaning, Second label learning
말 늦은 아동(late talker)은 초기 언어발달에서 어려움을 보이며, 특히 어휘 습득에서 두드러진 지체를 보인다. 일반적으로 어린 아 동들은 단어 학습을 위해 다양한 어휘적 원리(lexical principle)를 이용하여 단어의 소리와 의미를 효율적으로 연결(mapping)한다 (Behrend, 1990; Markman, 1990). 그중 상호배타성 가정(mutual exclusivity assumption)은 어휘 급증 시기에 아동의 빠른 단어 학 습을 도와주는 대표적인 어휘적 원리이다(Markman, Wasow, \& Hansen, 2003, Liittschwager \& Markman, 1994). 그러나 아동의 어 휘량이 증가함에 따라 상호배타성 가정을 무시하고 하나의 사물 에 관련된 다양한 어휘들을 습득하는 것도 필요하다(Hansen \& Markman, 2009; Markman \& Hutchinson, 1984). 본 연구에서는
말 늦은 아동이 단어와 의미를 연결할 때 상호배타성 가정을 활용 하거나 무시하는 양상을 또래 일반아동들과 비교하고자 하였다.

말 늦은 아동(late-talker)은 언어 이외 다른 영역(인지, 사회성, 대·소근육 운동발달 등)에서는 정상 발달을 보이나 표현언어 발달 에서 두드러진 지체를 보이는 3세 미만의 아동을 말한다(Paul, 1991, 1993; Rescorla, 1989, 1991; Thal \& Bates, 1988). 진단의 세부적인 기준은 연구자마다 차이가 있으나, 많은 연구자는 청력 손실의 병 력, 정신지체, 행동장애 및 신경학적 손상(구강, 운동, 감각 손상을 포함)이 없는 아동 중에서 표준화된 표현어휘발달검사에서 또래와 비교하였을 때 - $1 \mathrm{SD}$ 또는 $10 \%$ ile 미만의 언어 수준을 보이는 아동, 표현어휘가 10 개 미만인 18-23개월 아동, 또는 2 세나 3 세가 될 때까 
지 50 개 미만의 단어를 산출하거나 두 단어 조합이 출현하지 않는 아동을 그 기준으로 한다(Hong \& Kim, 2005; Paul, 1993; Paul, Looney, \& Dahm, 1991; Rescarla, Roberts, \& Dahlsgaard, 1997; Rescorla, 1989; Stark \& Tallal, 1981; Thal \& Bates, 1988). 이처럼, 어휘발달 수준은 말 늦은 아동의 중요한 진단 기준이다.

말 늦은 아동 중 일부는 3세 이후에도 표현어휘발달지체를 보이 거나 단순언어장애(SLI)로 진단되며, 학령기에 읽기장애나 학습장 애를 보일 위험성이 크다(Leonard, 1998; Paul, 1991; Rescorla, Roberts, \& Dahlsgaard, 1997). 이러한 사실은 말 늦은 아동의 조기 중 재의 필요성을 피력하며, 그 선행조건으로 말 늦은 아동이 보이는 주요 문제인 어휘 학습에서 말 늦은 아동들이 어떠한 특성을 보이 는지에 대한 연구가 필요하다. 구체적으로, 아동은 연속된 발화에 서 단어를 구별해 내고, 그 단어와 단어의 의미를 연결(mapping)해 야 하고, 궁극적으로 의미가 연결된 단어를 기억 및 저장하는 어휘 습득의 과정에서 말 늦은 아동들의 습득 기제가 일반아동들과 어 떻게 다른지를 이해하여야 한다. 국외에서는 말 늦은 아동의 언어 에 영향을 미치는 환경적 변인, 예후 및 예후예측인자, 언어영역별 특성 등 다양한 측면에서의 연구가 이루어졌고(D'Odorico, Assanelli, Franco, \& Jacob, 2007; Fasolo \& D’Odorico, 2002; Mirak \& Rescorla, 1998; Paul, Looney, \& Dahm, 1991; Preston et al., 2010; Rescorla, Bascome, Lampard, \& Feeny, 2001; Rescorla \& Roberts, 2002; Thal \& Bates, 1988), 단어의 의미 습득 및 학습에 대해서도 활발한 연구가 이루어졌다(Colunga \& Sims, 2011; Jones, 2003; Jones \& Smith, 2005; Kouri, 2005; Weismer, Murray-Branch, \& Miller, 1993). 그에 반해 말 늦은 아동과 관련된 국내 선행 연구들 은 예후 예측인자와 느린 언어발달에 영향을 주는 변인에 대한 연 구가 대부분이었고(Ha, 2012; Hong, 2007; Hong \& Kim, 2005; Sim \& $\mathrm{Ha}, 2014)$, 어휘습득에 대한 연구는 제한적이었다(Ji, 2013; Oh \& Yim, 2013). 따라서 본 연구에서는 말 늦은 아동이 새 단어를 듣고 의미를 연결하는 특성을 알아봄으로써 어휘 습득 시 말 늦은 아동 과 일반아동의 차이를 확인하고자 한다.

일반적으로 초기 단어 학습 시 아동은 다양한 어휘적 원리나 이 론을 이용하여 새 단어의 의미를 빠르게 연결하고 습득한다(Behrend, 1990; Markman, 1990). 단어학습과 관련된 어휘적 원리 중 전체 대상 가정(whole object assumption), 상호배타성 가정(mutual exclusivity assumption), 분류학적 가정(taxonomic assumption) 은 대표적인 어휘적 제약으로 지금까지 많은 연구가 이루어졌다(Liittschwager \& Markman, 1994; Markman, 1989, 1990; Markman \& Wachtel, 1988; Merriman, 1991; Merriman, Bowman, \& MacWhinney, 1989). 이 중 상호배타성 가정은 각 사물이 오직 하나의
이름만을 갖고, 각 이름은 오직 하나의 사물 범주만을 지시한다는 가정이다(Markman \& Wachtel, 1988). 이러한 상호배타성 가정은 어휘 급증 시기에 아동들의 빠른 단어 습득에 필수적인 역할을 하 고(Markman et al., 2003), 단어의 의미 연결 시 불필요한 가정을 줄 이면서 효율적인 단어 학습을 가능하게 한다(Liittschwager \& Markman, 1994). 선행 연구들은 2-3세뿐만 아니라 16 개월의 어린 아동 들도 새 단어의 의미 연결 과정에서 상호배타성 가정을 사용한다고 보고하였다(Cho, 1993; Ghim, 1994, 1997; Liittschwager \& Markman, 1994; Markman \& Wachtel, 1988; Mather \& Plunkett, 2009). 더불어 정상발달을 보이는 아동들뿐만 아니라 이중언어 습득 아 동과 언어습득에 어려움을 보이는 청각장애 아동, 윌리엄스증후군 아동, 자폐 아동 및 지적장애 아동도 단어 학습에서 상호배타성 가 정을 따른다고 보고하였다(Davidson \& Tell, 2005; Hong, 1994; Lederberg, Prezbindowski, \& Spencer, 2000; Preissler \& Carey, 2005; Stevens \& Karmiloff-Smith, 1997). 이처럼 상호배타성 가정은 언어 를 습득하는 초기부터 활용되는 중요한 원리임에도 불구하고 말 늦은 아동을 대상으로 한 상호배타성 연구는 찾기 어렵다.

그런데 상호배타성 가정에 따르면 한 가지 사물은 하나의 이름 만을 허용하지만, 실제로 한 사물은 여러 개의 이름을 갖기도 한다. 풍부한 어휘 발달을 위해서는 어휘 습득 과정에서 한 사물의 단일 이름뿐만 아니라 사물의 세부 부분, 특성을 나타내는 어휘, 동의어, 유의어 및 상위 범주어 등을 학습하는 것도 중요하다. 따라서 단어 를 학습할 때 아동이 상호배타성 가정에만 의지하여 단어의 의미 를 추론한다면, 아동은 제한적으로 어휘를 습득하게 된다. 이와 관 련하여 아동의 단어 학습에 관심을 가져온 많은 연구자는 어린 아 동들의 상호배타성 가정의 활용뿐만 아니라 상호배타성이 위배되 는 상황, 특히 화자의 의도가 상호배타성 가정에 반하는 방향으로 친숙한 사물과 단어의 의미 연결을 유도할 때, 아동이 어떤 단어 의 미 연결 특성을 보이는지에 대해서 연구하였다(Au \& Glusman, 1990; Jaswal \& Hansen, 2006; Jin, Kim, Kim, Yoon, \& Song, 2008; Lee, 2005; Liittschwager \& Markman, 1994).

어린 아동들은 단어의 의미를 추론할 때, 어휘적 제약을 활용할 뿐만 아니라 화자가 제시하는 언어 및 행동 단서를 통해 화자의 의 사소통 의도를 파악함으로써 이에 기반을 두고 단어의 의미를 파 악하기도 한다(Kobayashi, 1998; Lee, 2012). 이렇게 화자의 의도를 이해함으로써 단어의 의미를 파악하는 능력은 2 세의 아동에게서 도 나타난다(Jin et al., 2008). 일반아동을 대상으로 한 연구들에 따 르면 3세 아동들은 화자의 의도가 분명한 상황에서는 상호배타성 을 무시하고 친숙한 사물에 새로운 단어를 연결하였고, 24 개월의 아동들도 사물의 첫 번째 이름과 두 번째 이름을 모두 잘 학습하였 
던 반면 16 개월의 아동은 두 번째 이름 학습에 어려움을 보였다고 한다(Jin et al., 2008; Lee, 2005; Liittschwager \& Markman, 1994). 어린 아동들이 하나의 사물에 대해 하나 이상의 이름을 학습할 수 있다는 증거들은 다수 보고된 바 있다(Clark, 1987; Nelson, 1988; Waxman \& Hatch, 1992). 그러나 말 늦은 아동을 포함하여 언어 결함을 가진 아동들을 대상으로 하나의 사물에 하나 이상의 이름 을 학습하는 것이 가능한지를 살펴본 연구는 제한적이다.

본 연구에서는 먼저 2세(24-35개월)의 말 늦은 아동(late-talker) 이 새로운 단어를 들었을 때, 제시된 친숙한 사물과 낮선 사물 중에 서 선택하는 양상을 일반아동과 비교함으로써 이들이 상호배타성 가정을 활용하는지를 확인하고자 한다. 또한, 이미 이름을 알고 있 는 친숙한 사물에 대해 화자가 새 단어로 이름 붙이려는 의도를 직 접적으로 보여줬을 때, 말 늦은 아동들이 상호배타성 가정을 무시하 고 새 단어를 친숙한 사물과 연결할 수 있는지 확인해보고자 한다.

\section{연구 방법}

\section{연구대상}

연구 대상자는 만 24-35개월의 말 늦은 아동 14명(남아 9 명, 여아 5 명)과 생활연령이 일치하는 일반아동 15 명(남아 8 명, 여아 7 명)으 로 총 29명이었다. 대상자 선정은 육아 관련 인터넷 커뮤니티를 통 해 보호자의 자발적인 신청에 따라 이루어졌다.

말 늦은 아동의 선정 기준은 1$)$ 한국형 덴버 발달선별검사-II (K DDST-II: Shin, Han, Oh, Oh, \& Ha, 2002)에서 언어 이외의 모든 영역에서 정상 발달을 보이며, 2) 영유아 언어발달검사(SELSI: Kim, Kim, Yoon, \& Kim, 2003) 결과에서 표현언어 수준이 10\%ile 미만, 3) 한국형 맥아더-베이츠 의사소통 발달 지표(K M-B CDI: Pae \& Kwak, 2011)의 표현어휘 수준이 $10 \%$ ile 미만에 속하고, 4) 두 낱말 조합이 나타나지 않는 아동이었다.

일반아동의 선정 기준은 1) K DDST-II (Shin et al., 2002)의 모든 영역에서 정상 발달을 보이며, 2) SELSI (Kim et al., 2003)결과, 표현 언어 수준이 $10 \%$ ile 이상, 3) KM-B CDI (Pae \& Kwak, 2011)의 표현 어휘 수준이 $25 \%$ ile 이상에 속하고, 4) 두 낱말 조합 이상의 자발발 화를 산출하는 아동을 대상으로 하였다. 부모의 보고에 따르면 두 집단 아동들은 모두 시력, 청력을 포함한 감각, 기질 및 신경학적 손 상이 없고 언어치료 경험이 없었다. 두 집단 아동들의 기본정보는 Table 1에 제시하였다.

\section{도구}

실험에서 사용할 새 단어(novel words)는 3세 이전에 완전히 습
Table 1. Group characteristics

\begin{tabular}{|c|c|c|c|c|}
\hline \multirow{2}{*}{ Characteristic } & \multicolumn{2}{|c|}{ LT children $(N=14)$} & \multicolumn{2}{|c|}{ TD children $(N=15)$} \\
\hline & Mean & SD & Mean & SD \\
\hline Chronological age (mo) & 28.20 & 2.01 & 26.90 & 3.15 \\
\hline $\begin{array}{l}\text { SELSI (raw score) } \\
\text { Expressive language }\end{array}$ & 26.21 & 7.31 & 50.53 & 4.09 \\
\hline $\begin{array}{l}\text { K M-B CDI (raw score) } \\
\text { Expressive vocabulary }\end{array}$ & 31.07 & 33.11 & 441.20 & 173.57 \\
\hline
\end{tabular}

$\mathrm{LT}=$ late talking; $\mathrm{TD}$ = typically developing; $\mathrm{SELSI}=$ Sequenced Language Scale for Infants; K M-B CDI=Korean version of the MacArthur-Bates Communicative Development Inventories.

득되는 음소 /표, ㅁ, O(종성)/ 또는 숙달되는 음소 /ㅂ, 뻐, ㄴ, ᄃ, 匹, E, ᄀᄀ, T, ㄱ, 히로 구성된 CVCV 구조의 단어들로, 함께 제시 될 사물 이름과 구별되는 쉬운 소리의 단어들로 제작하였다. 최종 선정된 단어는 ‘보가, 디나, 니호, 모내, 푸티’ 모두 5개였다.

실험에서 사용할 사물 중 친숙한 사물은 K M-B CDI 검사 유아 용(Pae \& Kwak, 2011)을 참고하였고, 그중 18-30개월 아동의 75\%가 표현하는 것으로 보고한 항목으로 제한하여 선정하였다. 최종 선정 한 사물은 '자동차, 사과, 곰, 토끼, 숟가락'으로 모두 5개였다. 낮선 사물은 아동이 본 적이 없거나, 본 적이 있더라도 이름을 알기 어려 울 것이라고 예상되는 것 중 아동이 친숙한 사물로 유추할 가능성 이 있는 사물을 제외하여 선정하였다. 최종 선정된 사물은 “비전형 적 모양의 찜기, 먼지거름망, 비전형적인 모양의 독서용 라이트, 다용 도 고리, 비전형적인 모양의 화분 받침'으로 모두 5 개였다. 모든 사물 은 목표한 사물단어가 아닌 다른 단어로 유추할 가능성을 배제하 기 위해 무늬가 없는 것들로 선택하였고, 사진에서 사물의 가로와 세로 길이를 각각 $11 \pm 2 \mathrm{~cm}, 5 \pm 1 \mathrm{~cm}$ 로 제한하여 제시되는 사진 내 사물의 크기가 아동의 선택에 영향을 미치지 않도록 통제하였다.

본 연구에서 사용한 도구 항목들은 언어병리를 전공한 5년 이상 경력의 언어재활사 3 명에게 내용 타당도를 검증받았다. 검증 내용 은 친숙한 사물과 낯선 사물 항목의 적절성, 검사 도구(사물 사진) 의 명확성 그리고 새 단어의 적절성이었다.

과제의 수행 가능성 및 도구의 적절성 등을 알아보기 위해 24-35 개월의 일반아동과 말 늦은 아동(late talker) 각각 10 명을 대상으 로 예비실험을 시행하였다. 첫 번째, 친숙한 사물 선정의 적절성을 알아보기 위해 5 개의 사물을 제시한 후 이름대기 또는 사물의 이 름을 듣고 지적하기 과제를 실시하였고, 두 집단의 모든 아동이 5 개 사물의 이름을 정확하게 표현 또는 이해하였다. 두 번째, 낮선 사물 선정의 적절성을 알아보기 위해 5 개의 사물을 제시한 후 이름대기 혹은 새 단어를 듣고 지적하기 과제를 실시하였고, 두 집단의 모든 아동이 5 개의 사물의 이름을 모른다고 표현하거나 해당 사물을 적 

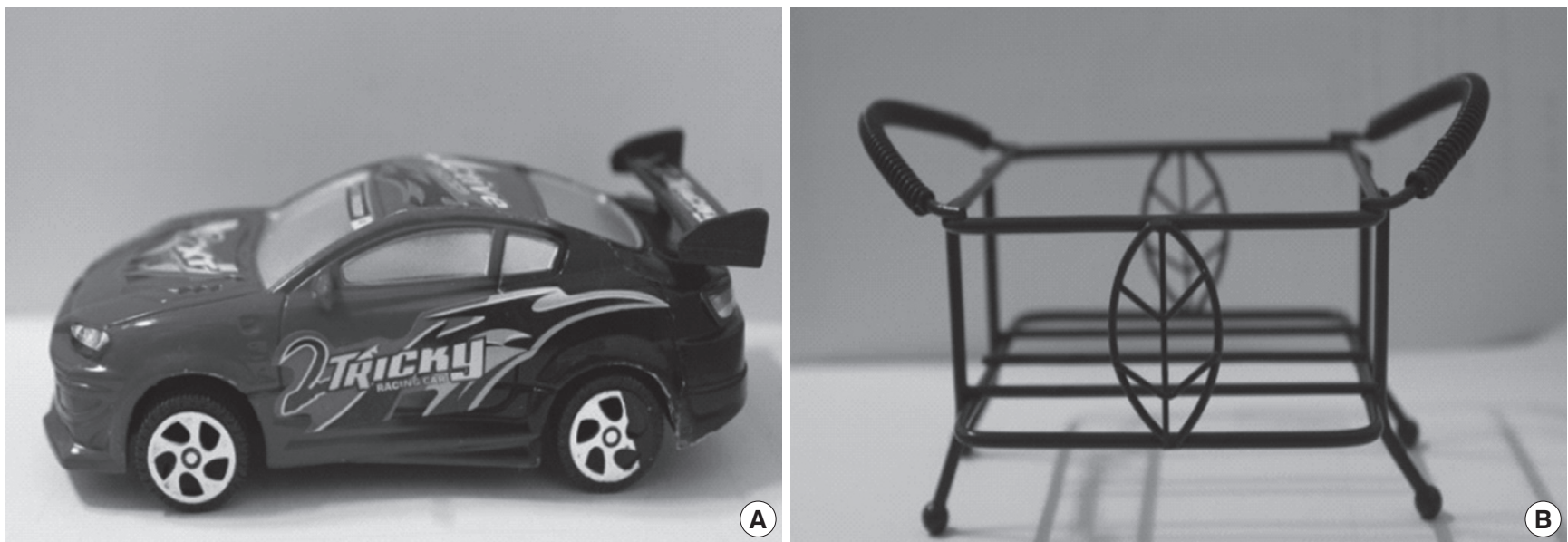

Figure 1. The examples of object photo. (A) Familiar object and (B) non-familiar object.

절하게 지적하지 못하였다. 세 번째, 제시하는 도구의 적절성을 알 아보기 위해 실제 사물과 그 사물들의 사진을 제시하였는데, 일부 아동들은 사물에 지나친 관심을 보이고 탐색함으로써 검사자의 구 어 지시에 대해 집중하지 못하였던 반면, 사물 사진을 제시하였을 때 검사자의 지시에 더 집중하여 반응하였다. 예비실험에서 관찰된 아동반응과 결과에 따라 예비실험에서 사용한 사물들로 최종 실 험 사물을 확정하였고, 제시하는 도구는 실제 사물의 사진으로 결 정하였다. 본 실험에서는 선정한 사물을 Canon EOS 500D로 촬영 하여 $105 \times 145 \mathrm{~mm}^{2}$ 의 규격으로 컬러 출력하여 실험 자료로 사용 하였다. 사물 사진에 대한 예시는 Figure 1과 같다.

\section{연구절차}

실험은 아동의 가정 내 조용한 공간에서 진행되었고, 검사자는 아동의 보호자와 인터뷰를 하는 장면을 아동에게 자연스럽게 보여 주며 검사자에 대한 아동의 경계를 줄이고자 하였다. 이후 검사자 는 5 분간 아동과 자유놀이를 통해 라포(rapport)를 형성하면서, 두 개의 사진 중 하나를 선택해야 하는 과제에 대해 아동이 이해하고 있는지 확인한 다음 실험을 시작하였다. 모든 아동에게 먼저 실험 1 을 실시한 후 과제에 대한 아동의 피로도 감소를 위해 1 분간 자유 놀이를 하게 하였고, 이후 실험 2를 실시하였다.

실험 1에서는 검사자는 아동에게 책상 위 $15 \mathrm{~cm}$ 간격으로 표시 해둔 위치에 두 개의 사물사진(친숙한 사물 사진과 낮선 사물 사 진)을 동시에 제시하였다. 검사자는 각각의 사물 사진을 하나씩 들 고 보여주면서 아동이 2 개의 사진 모두를 관찰하게 하였고, "여기 에 푸티가 있어요."라고 말해줌으로써 새 단어가 두 개의 사물 사 진 중 하나의 사물을 의미한다는 것을 알려주었다. 그 후, 검사자는 “푸티는 어디 있어요?”라고 말하며 새 단어가 지시하는 사물의 사
진을 아동이 선택하도록 유도하였다. 실험 1 에서 사물 사진은 낮선 사물과 친숙한 사물로 이루어진 사물 사진 5쌍을 제시하였는데, 친숙한 사물 사진 및 낯선 사물 사진의 제시 위치는 교대로 배치하 였다. 아동이 5 초가 지나도 어떤 사물의 사진도 선택하지 않는 경 우, “푸티는 어디 있어요?”라고 다시 물어 아동의 선택을 유도하였 고, 두 개의 사물의 사진을 모두 선택한 경우에는 "푸티 하나만 주 세요.”라고 말하였다. 그리고 아동이 “이게 푸티예요?”라고 확인 질문을 한 경우에는 “네가 생각한 대로 하면 돼."와 같이 중립적으 로 대답하였다. 검사자는 아동이 선택 반응을 한 이후에는 "잘했 어." 또는 “고마워.”와 같이 일관된 반응을 해주었다.

친숙한 사물의 두 번째 이름의 학습 여부를 확인하는 실험 2에 서, 검사자는 먼저 아동에게 친숙한 사물의 사진만을 보여주고 손 가락으로 가리키면서 새 단어를 연속해서 두 번 말해준 후 (예, "이 것은 푸티예요.”) 친숙한 사물사진을 제거하였다. 이후 검사자는 아동에게 책상 위 $15 \mathrm{~cm}$ 간격으로 표시해둔 위치에 두 개의 사물 사진(직전에 제시했던 친숙한 사물 사진과 낮선 사물 사진)을 동시 에 제시한 다음, 각각의 사물 사진을 하나씩 들고 보여주면서 아동 이 2 개의 사진 모두를 관찰하게 하였고, “푸티는 어디 있어요?”라 고 말하며 새 단어가 지시하는 물건을 아동이 선택하도록 유도하 였다. 실험 중 아동이 보인 반응에 대한 검사자의 반응은 실험 1 과 동일하였다.

\section{자료처리 및 분석}

실험 1에서는 아동이 상호배타성 가정을 활용(낮선 사물 선택) 한 반응 빈도의 합, 실험 2에서는 아동이 상호배타성 가정을 무시 (친숙한 사물 선택)한 반응 빈도의 합을 각각 기록하였다. 실험 1 과 2의 자료에 대해서 SPSS version 20.0 for Windows 프로그램을 사 
Table 2. Average frequency of selecting a non-familiar object in experiment 1

\begin{tabular}{lcccccc}
\hline & \multicolumn{2}{c}{$\begin{array}{c}\text { LT children } \\
(\mathrm{N}=14)\end{array}$} & & \multicolumn{2}{c}{$\begin{array}{c}\text { TD children } \\
(\mathrm{N}=15)\end{array}$} \\
\cline { 2 - 3 } \cline { 5 - 6 } & Mean & SD & & Mean & SD \\
\hline $\begin{array}{c}\text { Selecting a non-familiar object } \\
\text { (use of mutual exclusivity assumption) }\end{array}$ & 3.57 & 0.65 & & 3.80 & 0.68 \\
\hline
\end{tabular}

$\mathrm{LT}=$ late talking; $\mathrm{TD}=$ typically developing.

The total number of given chance was 5 times.

용하여 독립표본 $t$-검정을 실시하였다.

\section{연구 결과}

실험 1 에서는 아동들이 상호배타성 가정에 의거하여 새 단어를 낮선 사물과 연결하는 경향성을 조사하였다. 새 단어를 상호배타 성 가정에 따라 낮선 사물과 연결한 집단별 평균 빈도는 말 늦은 아 동들이 3.57 , 일반 아동들이 3.80 이었으며, 집단 간 차이는 통계적 으로 유의미하지 않았다 $\left(t_{(27)}=.929, p=.361\right)$. 실험 1 에서 아동들이 새 단어를 듣고 낮선 사물을 선택한 빈도의 집단별 평균과 $t$-검정 결과를 Table 2에 제시하였다.

각 집단 아동들이 상호배타성 가정을 따르는 경향성을 비율적 으로 비교하면, 말 늦은 아동들이 과제를 수행한 전체 반응 중 상호 배타성 가정을 따라 낮선 사물을 선택한 비율은 우연 수준을 넘는 반응이었고(71.4\%, Binomial test, $p<.001)$, 일반아동들이 낮선 사 물을 선택한 비율도 우연 수준을 넘는 반응이었다( $76 \%$, Binomial test, $p<.001)$.

실험 2에서는 화자가 새 단어로 친숙한 사물에 두 번째 이름을 붙이는 상황에서 아동들이 상호배타성 가정을 무시하고 새 단어 를 친숙한 사물과 연결하는 경향성을 조사하였다. 상호배타성 가 정을 무시하고, 새 단어를 친숙한 사물과 연결한 집단별 평균 빈도 는 말 늦은 아동들이 1.64 , 일반 아동들이 3.80 이었으며, 집단 간차 이는 통계적으로 유의미하였다 $\left(t_{(27)}=-6.811, p<.001\right)$. 실험 2에서 아동들이 새 단어를 듣고 친숙한 사물을 선택한 빈도의 집단별 평 균과 $t$-검정 결과를 Table 3 에 제시하였다.

실험 2에서 각 집단 아동들이 상호배타성 가정을 무시하는 경향 성을 비율적으로 비교하면, 말 늦은 아동들이 과제를 수행한 전체 반응 중 상호배타성 가정을 무시하고 친숙한 사물을 선택한 비율 은 $32.8 \%$ 로 우연 수준을 넘지 않았던 반면, 일반아동들이 친숙한 사물을 선택한 비율은 우연 수준을 넘는 반응이었다 $(76 \%$, Binomial test, $p<.001)$.
Table 3. Average frequency of selecting a familiar object in experiment 2

\begin{tabular}{|c|c|c|c|c|}
\hline & \multicolumn{2}{|c|}{$\begin{array}{l}\text { LT children } \\
\quad(\mathrm{N}=14)\end{array}$} & \multicolumn{2}{|c|}{$\begin{array}{l}\text { TD children } \\
(\mathrm{N}=15)\end{array}$} \\
\hline & Mean & SD & Mean & SD \\
\hline $\begin{array}{l}\text { Selecting a familiar object }{ }^{\mathrm{a}} \\
\text { (Ignore of mutual exclusivity assumption) }\end{array}$ & 1.64 & .84 & 3.80 & .86 \\
\hline
\end{tabular}

$\mathrm{LT}=$ late talking; $\mathrm{TD}=$ typically developing.

${ }^{a}$ The total number of given chance was 5 times.

\section{논의 및 결론}

본 연구에서는 두 개의 실험을 통하여 24-35개월의 말 늦은 아동 과 일반아동을 대상으로 새 단어의 의미 연결 시 상호배타성 가정 활용과 친숙한 사물에 대한 두 번째 이름의 학습 상황에서 새 단어 의미 연결 특성을 조사하였다.

실험 1에서 새 단어를 들었을 때 낮선 사물을 선택한 수행 비율 은 말 늦은 아동이 $71.4 \%$, 일반아동이 $76 \%$ 로 두 집단 모두 상호배 타성 가정을 활용하는 경향을 보였다. 또한, 두 집단 아동들이 낮선 사물을 선택한 빈도는 유의미한 차이를 보이지 않았다. 실험 1에서 나타난 일반아동들의 수행은 21-23개월 아동들도 새 단어의 의미 를 추론할 때 상호배타성 가정을 활용하고(Ghim, 1997), 2세 아동 도 새 단어를 듣고 친숙한 사물보다 낯선 사물을 유의미하게 더 많 이 선택한다는 선행 연구 결과와 일치한다(Golinkoff, Hirsh-Pasek, Lavallee, \& Baduini, 1985; Hutchinson, 1986). 이처럼 어휘발달 이 느린 말 늦은 아동들도 일반아동들과 유사한 정도로 새 단어를 낮선 사물과 연결한다는 사실은 상호배타성 가정이 어린 아동들의 어휘 습득과정에서 매우 강력하게 작용하는 어휘적 원리임을 보여 준다. 그러나 상호배타성 가정의 활용이 언어 발달의 지체 여부에 전혀 영향을 받지 않는 것은 아니다. Hong (1994)에 따르면 2-4세 수준의 정신연령을 가진 지적장애 아동도 상호배타성 가정에 따라 단어 의미를 추론하는 경향을 보였으나, 이러한 경향은 전체 아동 들 중 $44 \%$ 정도였다. 즉, 언어발달에 어려움을 겪는 아동들도 상호 배타성 가정을 활용하지만 그 편향성에선 집단에 따라차이가 있다. 반면, 실험 2에서 말 늦은 아동들이 새 단어의 의미를 친숙한 사 물의 두 번째 이름으로 연결시킨 비율은 $32.8 \%$ 로, Liittschwager와 Markman (1994)의 16 개월 일반아동이 보여준 $52 \%$ 에 비해 낮았 다. 즉, 2 세 말 늦은 아동은 또래 일반아동들뿐만 아니라 생활연령 이 더 어린 아동들에 비해서도 더욱 두드러진 상호배타성 편향을 보인다는 것을 의미한다. 말 늦은 아동들은 화자가 새 단어를 친숙 한 사물과 분명하게 연결하는 상황에서도 어휘적 제약인 상호배타 성 가정에서 벗어나지 못하여 사물의 두 번째 이름을 학습을 어려 
워하는 것으로 보인다. 말 늦은 아동의 이러한 특성은 한 사물에 여 러 이름을 허용해야만 습득이 가능한 사물의 세부 부분이나 특성 을 나타내는 어휘, 유의어 및 범주어 등의 학습을 어렵게 만들 수 있다. 이와 같은 맥락에서 말 늦은 아동의 유연하지 못한 단어의미 연결은 느린 어휘 발달에 영향을 미칠 것이라고 예상된다.

말 늦은 아동이 친숙한 사물의 두 번째 이름 학습에서 어려움을 보인 이유는 우선, 말 늦은 아동의 부족한 공동주의하기(joint attention)능력 때문일 수 있다. 말 늦은 아동은 공동주의하기 기능이 현저히 떨어지기 때문에(Paul, 1991), 화자가 가리키기(pointing)를 이용하여 친숙한 사물과 새 단어를 연결하는 상황에 대해 충분한 주의를 기울이지 못할 수 있다. 따라서 말 늦은 아동은 화자의 분명 한 의도를 파악하지 못하고 강력한 인지적 제약인 상호배타성 가 정에 따라 새 단어의 의미를 연결하게 되는 것이다. 또한, 말 늦은 아동의 빠른 의미연결(fast-mapping) 능력이 일반아동에 비해 유 의미하게 낮기 때문에(Ji, 2013), 새 단어의 의미 연결을 위해서 새 단어와 친숙한 사물 연결의 노출빈도 또한 더 많이 요구될 것으로 예상될 수 있다.

두 실험의 결과를 종합해보면 말 늦은 아동이 보인 상호배타성 편향은 사물의 첫 번째 이름 학습에서는 효율적으로 단어 학습을 도와주며 긍정적인 영향을 미치지만, 사물의 두 번째 이름 학습에 서는 부정적 영향을 미치는 것으로 보인다. 이러한 새 단어의 의미 연결 시 보이는 말 늦은 아동의 특성은 임상에서 말 늦은 아동의 어 휘습득 촉진을 위한 중재 목표 및 활동을 계획할 때 고려해야 할 중 요한 정보가 될 것이다.

이후 추가적으로 24 개월보다 더 어린 연령의 말 늦은 아동들도 새 단어의 의미 연결 시 상호배타성 가정을 활용하는지 확인함으 로써, 상호배타성 가정의 활용이 시작되는 시기에 대한 정보를 얻 는 것은 의미가 있을 것이다. 또한, 말 늦은 아동으로 진단받았던 36 개월 이상의 아동에 대한 후속연구를 통해 상호배타성을 무시하 고 친숙한 사물에 여러 개의 이름을 허용하는 능력의 발달이 언제 이루어지는 확인하는 것은 말 늦은 아동의 어휘 습득 및 발달을 이 해하는 데 도움을 줄 것이다. 뿐만 아니라 말 늦은 아동의 선정조건 에서 제스처의 발달수준, 조음음운능력 등을 고려한다면, 말 늦은 아동의 하위 집단에 대한 더 구체적인 정보를 얻을 수 있을 것이다.

\section{REFERENCES}

Au, T. K. F., \& Glusman, M. (1990). The principle of mutual exclusivity in word learning: to honor or not to honor? Child Development, 61, 1474-1490.

Behrend, D. A. (1990). The development of verb concepts: children's use of verbs to label familiar and novel events. Child Development, 61, 681-696.

Cho, K. J. (1993). The mutual exclusivity assumption in children's acquisition of word meaning (Master's thesis). Chungbuk National University, Cheongju, Korea.

Clark, E. V. (1987). The principle of contrast: a constraint on language acquisition. In B. MacWhinney (Ed.), Mechanisms of language acquisition (pp. 1-33). Hillsdale, NJ: Lawrence Erlbaum Associates.

Colunga, E., \& Sims, C. E. (2011). Early talkers and late talkers know nouns that license different word learning biases. In Proceedings of the 33th Annual Conference of the Cognitive Science Society (pp. 2550-2555). Austin, TX: Cognitive Science Society.

Davidson, D., \& Tell, D. (2005). Monolingual and bilingual children's use of mutual exclusivity in the naming of whole objects. Journal of Experimental Child Psychology, 92, 25-45.

D’Odorico, L., Assanelli, A., Franco, F., \& Jacob, V. (2007). A follow-up study on Italian late talkers: development of language, short-term memory, phonological awareness, impulsiveness, and attention. Applied Psycholinguistics, 28, 157-169.

Fasolo, M., \& D’Odorico, L. (2002). Vocabulary development of late-talking children: a longitudinal research from eighteen to thirty months of age. Rivista di Psicolinguistica Applicata, 3, 13-21.

Ghim, H. R. (1994). Evidence for and against the mutual exclusivity assumption: by Korean 3-year-old children and adults. Korean Journal of Psychology: Development, 7, 1-23.

Ghim, H. R. (1997). The principle of mutual exclusivity as a universal constraint on word meaning by 21- to 23-month-old Korean infants. The Korean Journal of Human Development, 4, 19-31.

Golinkoff, R. M., Hirsh-Pasek, K., Lavallee, A., \& Baduini, C. (1985). What's in a word? The young child's predisposition to use lexical contrast. In Boston University Conference on Child Language, Boston, MA.

Ha, E. B. (2012). Comparison of temperament and mother-children communicative characteristics between late-talker and normal children (Master's thesis). Dankook University, Yongin, Korea.

Hansen, M. B., \& Markman, E. M. (2009). Children's use of mutual exclusivity to learn labels for parts of objects. Developmental psychology, 45, 592-596.

Hong, G. H. (2007). A longitudinal study of communicative intention variables for predicting expressive vocabulary development of the 'late-talkers'. Korean Journal of Early Childhood Special Education, 7, 97-115.

Hong, G. H., \& Kim, Y. T. (2005). A longitudinal study of predictors for expressive vocabulary development of late-talkers. Korean Journal of Com- 
munication Disorders, 10, 1-24.

Hong, J. S. (1994). The reasoning about word meanings in normal and mentally retarded children (Master's thesis). Youngnam University, Gyeongsan, Korea.

Hutchinson, J. (1986). Children's sensitivity to the contrastive use of object category terms. Papers and Reports on Child Development, 25, 49-56.

Jaswal, V. K., \& Hansen, M. B. (2006). Learning words: Children disregard some pragmatic information that conflicts with mutual exclusivity. Developmental Science, 9, 158-165.

Ji, J. H. (2013). The effects of gestures on fast mappong of verbs with late-talkers (Master's thesis). Dankook University, Yongin, Korea.

Jin, K. S., Kim, M. Y., Kim, Y. J., Yoon, E. J., \& Song, H. J. (2008). Three- to four-year-old Korean children's use of mutual exclusivity and pragmatic cues in word learning. Korean Journal of Psychology: Development, 21, 4967.

Jones, S. S. (2003). Late talkers show no shape bias in a novel name extension task. Developmental Science, 6, 477-483.

Jones, S. S., \& Smith, L. B. (2005). Object name learning and object perception: a deficit in late talkers. Journal of Child Language, 32, 223-240.

Kim, Y. T., Kim, K. H., Yoon, H. R., \& Kim, H. S. (2003). Sequenced Language Scale for Infants (SELSI). Seoul: Special Education Publishing.

Kobayashi, H. (1998). How 2-year-old children learn novel part names of unfamiliar objects. Cognition, 68, B41-B51.

Kouri, T. A. (2005). Lexical training through modeling and elicitation procedures with late talkers who have specific language impairment and developmental delays. Journal of Speech, Language, and Hearing Research, 48, 157-171.

Lederberg, A. R., Prezbindowski, A. K., \& Spencer, P. E. (2000). Word-learning skills of deaf preschoolers: the development of novel mapping and rapid word-learning strategies. Child Development, 71, 1571-1585.

Lee, H. J. (2005). Mutual exclusivity constraint versus intention in word learning: based on Korean data. Korean Journal of Psychology: Development, 18, 79-95.

Lee, H. J. (Trans.) (2012). Language development (4th ed.). Seoul: Cengage Learning Korea Ltd.

Leonard, L. B. (1998). Children with specific language impairment. Cambridge, MA: MIT Press.

Liittschwager, J. C., \& Markman, E. M. (1994). Sixteen- and 24-month-olds' use of mutual exclusivity as a default assumption in second-label learning. Developmental Psychology, 30, 955-968.
Markman, E. M. (1989). Categorization and naming in children: problems of induction. Cambridge, MA: MIT Press.

Markman, E. M. (1990). Constraints children place on word meanings. Cognitive Science, 14, 57-77.

Markman, E. M., \& Hutchinson, J. E. (1984). Children's sensitivity to constraints on word meaning: taxonomic versus thematic relations. Cognitive Psychology, 16, 1-27.

Markman, E. M., \& Wachtel, G. F. (1988). Children's use of mutual exclusivity to constrain the meanings of words. Cognitive Psychology, 20, 121-157.

Markman, E. M., Wasow, J. L., \& Hansen, M. B. (2003). Use of the mutual exclusivity assumption by young word learners. Cognitive Psychology, 47, 241275.

Mather, E., \& Plunkett, K. (2009). Learning words over time: the role of stimulus repetition in mutual exclusivity. Infancy, 14, 60-76.

Merriman, W. E. (1991). The mutual exclusivity bias in children's word learning: a reply to Woodward and Markman. Developmental Review, 11, 164191.

Merriman, W. E., Bowman, L. L., \& MacWhinney, B. (1989). The mutual exclusivity bias in children's word Markman learning. Monographs of the Society for Research in Child Development, 54, 1-132.

Mirak, J., \& Rescorla, L. (1998). Phonetic skills and vocabulary size in late talkers: concurrent and predictive relationships. Applied Psycholinguistics, 19, 1-17.

Nelson, K. (1988). Constraints on word learning? Cognitive Development, 3 , 221-246.

Oh, D. Y., \& Yim, D. S. (2013). Non-word repetition and sentence repetition performance in 2-3 years old late talkers and normal children. Communication Sciences and Disorders, 18, 277-287.

Pae, S. Y., \& Kwak, K. J. (2011). MacArthur-Bates communicative development inventory-Korean: words and gestures. Seoul: Mind Press.

Paul, R. (1991). Profiles of toddlers with slow expressive language development. Topics in Language Disorders, 11, 1-13.

Paul, R. (1993). Patterns of development in late talkers: preschool years. Journal of Childhood Communication Disorder, 15, 7-14.

Paul, R., Looney, S. S., \& Dahm, P. S. (1991). Communication and socialization skills at ages 2 and 3 in late-talking young children. Journal of Speech, Language, and Hearing Research, 34, 858-865.

Preissler, M. A., \& Carey, S. (2005). The role of inferences about referential intent in word learning: evidence from autism. Cognition, 97, B13-B23.

Preston, J. L., Frost, S. J., Mencl, W. E., Fulbright, R. K., Landi, N., Grigoren- 
ko, E., ... Pugh, K. R. (2010). Early and late talkers: school-age language, literacy and neurolinguistic differences. Brain, 133, 2185-2195.

Rescorla, L. (1989). The language development survey: a screening tool for language delay in toddlers. Journal of Speech and Hearing Disorders, 54, 587-599.

Rescorla, L. (1991). Identifying expressive language delay at age two. Topics in Language disorders, 11, 14-20.

Rescorla, L., Bascome, A., Lampard, J., \& Feeny, N. (2001). Conversational patterns in late talkers at age 3. Applied Psycholinguistics, 22, 235-251.

Rescorla, L., \& Roberts, J. (2002). Nominal versus verbal morpheme use in late talkers at ages 3 and 4. Journal of Speech, Language, and Hearing Research, 45, 1219-1231.

Rescorla, L., Roberts, J., \& Dahlsgaard, K. (1997). Late talker at 2: outcome at age 3. Journal of Speech, Language, and Hearing Research, 40, 556-566.

Shin, H. S., Han, K. J., Oh, K. S., Oh, J. J., \& Ha, M. N. (2002). Korean Denver II. Seoul: Hyunmoonsa.
Sim, H. R., \& Ha, S. H. (2014). Comparison of phonological development between typically developing children and late talking children aged 18-30 months. Communication Sciences \& Disorders, 19, 99-112.

Stark, R. E., \& Tallal, P. (1981). Selection of children with specific language deficits. Journal of Speech and Hearing Disorders, 46, 114-122.

Stevens, T., \& Karmiloff-Smith, A. (1997). Word learning in a special population: do individuals with Williams syndrome obey lexical constraints? Journal of Child Language, 24, 737-765.

Thal, D., \& Bates, E. (1988). Language and gesture in late talkers. Journal of Speech and hearing Research, 31, 115-123.

Waxman, S. R., \& Hatch, T. (1992). Beyond the basics: preschool children label objects flexibly at multiple hierarchical levels. Journal of Child Language, 19, 153-166.

Weismer, S. E., Murray-Branch, J., \& Miller, J. F. (1993). Comparison of two methods for promoting productive vocabulary in late talkers. Journal of Speech, Language, and Hearing Research, 36, 1037-1050. 


\section{국문초록}

\section{4-35개월 말 늦은 아동의 새 단어 의미 연결 특성: 상호배타성 가정 활용을 중심으로 최일란 ${ }^{1}$ 황민아 \\ 1단국대학교 특수교육대학원, ${ }^{2}$ 단국대학교 특수교육학과}

배경 및 목적: 본 연구에서는 초기 언어발달단계의 어휘습득에 영향을 미치는 상호배타성 가정의 활용을 중심으로 말 늦은 아동의 새 단어 의미 연결 특성을 조사하였다. 방법: 연구대상은 24-35개월의 말 늦은 아동 14 명과 일반아동 15 명이었다. 실험 1 에서는 검사자가 말해주는 새로운 단어(예, 보가)를 듣고 친숙한 사물 사진과 낮선 사물 사진 중에서 하나를 고르게 하였고, 아동이 상호배타성 가정을 따른(낮선 사물 선택) 반응빈도를 측정하였다. 실험 2에서는 검사자가 아동에게 친숙한 사물 사진을 보여주며 새로운 단어(예, 푸티)를 그 사물의 이름이라고 알려준 뒤, 실험 1과 동일한 과제를 실시했을 때, 아동이 상호배타성 가정을 무시한(친숙한 사물 선택) 반응빈도 를 측정하였다. 결과: 실험 1 에서 두 집단은 모두 상호배타성 가정을 활용하여 새 단어의 의미를 연결하였고, 두 집단 간 수행에 유의미 한 차이가 없었다. 실험 2에서 일반아동은 상호배타성 가정을 무시하고 새 단어를 친숙한 사물의 두 번째 이름으로 연결하는 반면 말 늦은 아동은 여전히 상호배타성 가정에 따라 새 단어의 의미를 낮선 사물과 연결하는 경향을 보였다. 논의 및 결론: 본 연구 결과에서 나타난, 말 늦은 아동이 보이는 상호배타성 편향은 사물의 첫 번째 이름 학습에는 유용하나 하나의 사물에 연관되는 다양한 어휘의 습 득을 제한할 가능성이 있다.

핵심어: 말 늦은 아동, 상호배타성 가정, 단어 의미 연결

본 논문은 제 1 저자의 석사학위논문을 수정·보완하였음.

\section{참고문헌}

김영태, 김경희, 윤혜련, 김화수(2003). 영·유아 언어발달 검사(SELSI). 서울: 도서출판 특수교육.

김혜리(1994). 단어의미 추론 과정에 나타나는 상호배타성 가정: 긍정적 증거와 부정적 증거. 한국심리학회지: 발달, 7, 1-23.

김혜리(1997). 단어의미 추론에 작용하는 상호배타성 가정: 생후 21-23개월 된 영아의 자료. 인간발달연구, 4, 19-31.

배소영, 곽금주(2011). 한국형 맥아더-베이츠 의사소통발달 평가(KM-B CDI). 서울: 마인드프레스.

신희선, 한경자, 오가실, 오진주, 하미나(2002). 한국형 Denver II 검사. 서울: 현문사.

심혜림, 하승희(2014). 18-30개월 말 늦은 아동과 일반 아동의 음운 발달 비교. 언어청각장애연구, 19, 99-112.

오다연, 임동선(2013). 2-3세 말 늦은 아동과 정상 아동의 비단어 따라 말하기와 문장 따라 말하기 수행 능력. 언어청각장애연구, 18, 277-287.

이현진(2005). 단어의미 추론에서 상호배타성제약과 의도의 역할: 한국어 자료를 중심으로. 한국심리학회지: 발달, 18, 79-95.

이현진(역)(2012). 언어발달 제4판. 서울: 센게이지러닝코리아.

조경자(1993). 아이들이 단어의미 획득 과정에서 보이는 상호배타성 가정. 충북대학교대학원 석사학위논문.

지정희(2013). 몸짓(gesture)이 말 늦은 유아(late talker)의 빠른 의미연결(fast-mapping)에 미치는 효과. 단국대학교대학원 석사학위논문.

진경선, 김민영, 김유진, 윤정은, 송현주(2008). 3, 4세 한국 아동의 단어 학습에서 상호배타성과 화용 단서의 역할. 한국심리학회지: 발달, 21, 49-67.

하은빈(2012). 말 늦은 아동(late-talker)과 일반아동의 기질 및 어머니-아동간 의사소통 특성 비교. 단국대학교대학원 석사학위논문.

홍경훈(2007). '말 늦은 아동’의 표현어휘발달 예측을 위한 의사소통의도 산출특성 종단연구. 유아특수교육연구, 7, 97-115.

홍경훈, 김영태(2005). 종단연구를 통한 '말 늦은 아동(late-talker)'의 표현어휘발달 예측요인 분석. 언어청각장애연구, 10, 1-24.

홍지숙(1994). 정신지체아동의 단어의미 추론 양식의 비교. 영남대학교대학원 석사학위논문. 